\title{
Para el Mundo: Challenges and opportunities in Mancora, Peru
}

$\mathrm{P}$ ara el Mundo is a volunteer clinic established in 2005 by a paramedic from Toronto who saw the need for a primary care clinic in Mancora, a small town of 14,000 skirting the coastal desert of northern Peru. Since the clinic's opening, it has served the local population with the assistance of a volunteer general practitioner from Oregon, a paramedic trained in Toronto, local nurses, assistants, and volunteer medical students from across North America. Class of 2009 member Kevin Spencer first learned of the clinic in 2005 while traveling and returned to volunteer along with myself in June 2006.

Mancora is a remote town $1165 \mathrm{~km}$ north of Lima, Peru and $165 \mathrm{~km}$ south from the border of Ecuador. From the nearest airport in Piura I carpooled in a 'Collectivo', an Americanbuilt El Dorado, fitted with sticky vinyl bench seats along with room for seven locals. I reached Mancora via the infamous Pan-American Highway which weaves through a mountainous coastal desert, littered with blowing trash and abandoned oil pumps. The local industries include fishing, oil and tourism. However, the unemployment rate remains high.

The few backpackers and tourists venturing to the area will have undoubtedly read the Lonely Planet guidebook description of Mancora: "Peru's best year-round beach area boasting warm water, safe beaches, traveler friendly lodgings and surfing". Most visitors rarely leave the beach, missing the poverty-stricken parts of town. Many areas lack decent sanitation and public services. Behind the beachfront, dirt roads lead into rows of houses made of concrete and stucco, scrap materials and mud, while children and stray dogs play in the streets.

Para el Mundo is located on the first floor of a two storey house. Patients present at the evening clinics with a variety of routine and extraordinary complaints and fill the large white reception room. At the triage station, local nurses and volunteers record vitals and presenting problems amidst the almost silent crowd. In the corner, a heap of used, donated hospital beds and outdated computer equipment sits unused.

Frequent concerns such as the flu, skin rashes, childhood illnesses, sexual health, diabetes and joint pain are contrasted by more urgent and unusual cases. As one of only two physicians' offices in Mancora and the only free alternative, the staff see frequent trauma, congestive heart failure, parasites, wounds and respiratory complaints. Because of poor sanitation and limited health care access, many patients present with problems rarely seen in North America, including chronically infected wounds, limbs requiring amputation and chronic parasitic infections.

As volunteers, Kevin and I helped out with patient histories and physicals, along with the occasional routine treatment. Patients would smile and take extra time to speak slowly and act out confusing words to help bridge the language barrier. The smiles and body language made it obvious that patients felt relieved to be meeting with people interested in helping them.

The relaxed South American attitude and language barrier made for a unique experience. A man presenting three days after a car crash had facial lacerations and what appeared to be a detached retina. The clinic could offer little help and despite his failing vision, he appreciated the encounter, asking questions but never complaining or becoming angered at the helplessness of the situation.

As first year medical students familiar with a rich, resourceful system in Canada, we were struck by the seemingly impossible challenge the clinic faced: caring for so many people with so few resources. A significant number of patients needed medical attention that only large urban centers could provide. Elderly patients were diagnosed with diabetes regularly and offered a month's supply of insulin that the clinic had received from donations. As supplies ran out, there was no re-stocking.

The constant shortage of supplies was periodically relieved by donations from volunteers and staff people and augmented by a program "Not Just Tourists" which matches personal drug and medical supply donations to help provide much needed supplies to Cuba, the Caribbean and Central America (http://www.njttoronto.ca/). Volunteers donate, sort, pack, and carry medical supplies in suitcases to regions in need. Common items were the most difficult to keep stocked and simple donations of gauze, tape, urinalysis strips and antibiotic ointments were always needed.

While the staff at Para el Mundo cannot stay in Peru forever, they are trying to implement a system that will be sustainable for the future. Teaching the local assistants and nurses, educating patients in Mancora, and spreading the word about their wonderful program are a few of the ways in which they 
hope to continue the clinic into 2007. The clinic is currently searching for a physician to start in 2008 when the current family physician returns to Oregon with his family.

As students finishing the first year of medical school, helping out at the Para el Mundo clinic provided a glimpse into the disparities that health care professionals around the world are forced to deal with. Patients were grateful for the physicians' time and treatments; when little else was possible, the comfort and care were visibly appreciated. In the end, wanting to make a donation, we helped with a simple yet tangible improvement, providing wiring and lights so that the clinic could work past sunset.

For further information or opportunities to get involved, check the website: http://www.paraelmundo.org.

\section{John Haverstock}

Class of 2009, Faculty of Medicine, Dalhousie University

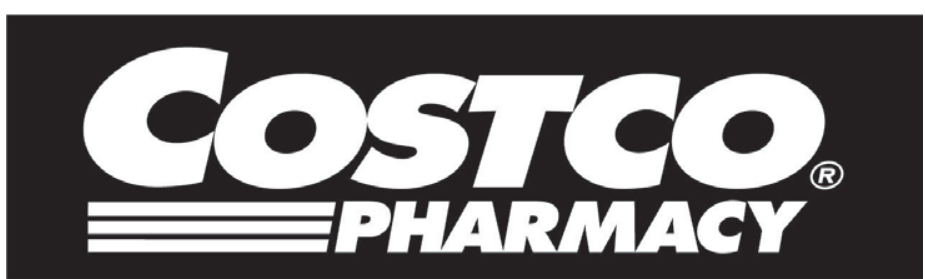

\section{Congratulation to all the Grads}

Best of luck in your future endeavours 